\title{
A Electrical and Optical Characteristics of Stannous Doped Nickel Oxide Thin Film Formed by Spray Pyrolysis Technique
}

\author{
P.Saritha
}

\begin{abstract}
Stannous slight film doped nickel oxide arranged on a glass substrate at $360^{\circ} C$ with a splash pyrolysis strategy. Nio: Sn films framed on various proportions, for example, $0.1 \mathrm{M}$ molarity: 0.01M and 0.lM: 0.03M. The movies were discovered uniform and follower to the substrate. its thickness was estimated utilizing a miniaturized scale balance technique. the electrical obstruction is estimated by a PC controlled Keithley electrometer and ingestion and vitality band hole determined for various wavelengths utilizing a spectrophotometer Elico cosmetics. high straightforwardness (above 80\%) in the obvious locale is accomplished and profoundly execute Nio films acquired when doped with Stannous.
\end{abstract}

Keywords - Nickel chloride; Stannous chloride; Spray Pyrolysis; Micro balance method; Electrical properties; Optical properties and Thin films

\section{INTRODUCTION}

A moderate layer of robust fabric on a strong substrate this is framed by means of the buildup of fuel iotas or debris or particles both by way of bodily or artificial strategies alluded to as a slim movie. using technological know-how narrow movie has gotten extraordinary reaction as it's miles utilized in certainly one of a kind mechanical fields of devices, navy weapon frameworks, sun oriented energy utilization, space frameworks actually as film substances optical and notable-directing component pc excessive reminiscence, sensors and microelectronics and half of and half of circuit and others.

Dainty movies applied in photo voltaic devices and sunlight hours based definitely cells that convert the strength of solar oriented radiation into useful electric powered power. Albeit numerous strategies are on hand to store meager movies, this work become finished by the use of utilizing pyrolytic bathe. for example: CdS, CU2S, CDO, $\mathrm{Cu} 2 \mathrm{O}$ may be spared thru using splash pyrolysis.

The Thermal decay (or) technique for pyrolysis for some halide or organometallic mixes while warmed to excessive temperatures breaks down bringing approximately the affiliation of sturdy and vaporous level. by way of and massive a few levels of auxiliary gasoline moreover brought which might then be capable of be disintegrated with the proper strong movie. alongside these lines, whilst the silicon organometallic mixes, as an example, tetra ethoxy silane, tetra ethylene ortho silicate (TEOS) and so forth. The fluid in (temp) shape is warmed to a temperature of spherical

Revised Manuscript Received on September 14, 2019.
Dr.P.Saritha, Assistant Professor, Department of Physics, Govt.
College of Engineering, Thanjavur 613 402,Tamil Nadu, India. (E-mail: College of Engineering,
psarithaau@yahoo.com) seven hundred-900 ${ }^{\circ} \mathrm{C}, \mathrm{SiO} 2$ dielectric film is fashioned as appeared with the useful resource of following eqn,

$\mathrm{Si}(\mathrm{OC} 2 \mathrm{H} 5)$ four decays into $\mathrm{SiO} 2+4 \mathrm{C} 2 \mathrm{H} 4+\mathrm{H} 2 \mathrm{O}$

\section{SLIM FILM TECHNIQUE DEPOSITS}

\section{1. physical Vapor Deposition}

inside the physical fume testimony method fume transport from the deliver to the substrate takes place in a bodily manner. this is done by means of collapsing affidavit essentially in a vacuum for it that implies loose way of fuel atoms are debris larger than the components of the assertion chamber and assets within the substrate. bodily fume testimony is advanced make use of the vacuum dissipation (or) the sputtering approach.

\section{2. synthetic Deposition}

This method is predicated upon the film declaration from a watery arrangement either through passing a flow or via the usage of a compound response underneath the nice possible situations and are commonly implemented for the affidavit of thick metallic or mixture movies. by means of the idea of the scenario preparative them those films are usually not excessive immaculateness - despite these constraints is typically applied for the assembling of doing the connector component appealing memory and so forth. With suitable manage parameters of testimony because the organisation of the shower, temperature, $\mathrm{pH}$, modern-day thickness, and so on stores metal or even the mixture of particular advent may be gotten.

2.three. Compound fume affidavit

film assertion from the gasoline degree with the useful resource of heat disintegration (pyrolysis) or concoction response on the outdoor of the substrate at a excessive temperature manner referred to as compound fume affidavit (CVD) or fume plating. This technique is utilized for the making plans of an collection of inorganic and herbal mixes. The essential massive includes the decay or separations bit of fume degree species and their consequent testimony on a substrate or a response between the fume species in an independent surroundings or the opposite manner round, and the affidavit of the item. In some instances the transporter gas is supplied moreover useful for controlling the tempo of response or to hold a strategic distance from undesirable response at immoderate temperatures triumphing. genuine manage of the movement tempo of gas species, the 


\section{A ELECTRICAL AND OPTICAL CHARACTERISTICS OF STANNOUS DOPED NICKEL OXIDE THIN FILM FORMED BY SPRAY PYROLYSIS TECHNIQUE}

temperature and weight of the reaction chamber prompts the development of a store is needed.

Some of the reactions specifying the formation of films are given below:

AB decomposes to $\mathbf{A}+\mathbf{B}$

$\mathbf{A B}+\mathbf{C D}$ dissociate to $\mathbf{A C}+\mathbf{B D}$ (or) $\mathbf{A}+\mathbf{B C D}$ etc.

$2 \mathrm{AB2}$ dissociate to $\mathbf{A B}_{4}+\mathbf{A}$ etc.

$(\mathrm{AB})_{\mathbf{n}}$ dissociate to $\mathbf{n A}+\mathbf{n B}$

Where, $A, B, C$ and $D$ are different constituents and $n$ is an integer.

\subsection{Electro chemical deposition}

When a current is passed through an aqueous solution of some metal salts between two electrodes of the same or different metals, the deposition of metal from the aqueous solution takes place at the cathode surface following the faraday's law,

$\mathbf{W}=$ Zit $\alpha$

Where, w - weight of the metal deposited, $\mathrm{z}$ - electro chemical equivalent

$\mathrm{i}$ - current passed , $\mathrm{t}$ - time of deposition and $\alpha$ - cathode efficiency

The keep going term yet relying upon different factors, for example, shower creation, $\mathrm{pH}$, temperature, current thickness and so on statement component includes separation of the metal salt to anions and cations of the keep going testimony on the cathode surface and balance because of their charge to shape a metallic film. In the electro-plating anodes are for the most part of a similar metal to be stored on the cathode. Now and again dissolvable anodes are utilized. At the point when some time went through the shower arrangement, the measure of metal stored on the cathode is given by eqn (1) and the suitable measure of metal from the anode into the arrangement. The anode response to divalent metal salt shower can be communicated by the accompanying condition,

$$
\mathrm{M}^{++}+2 \mathrm{e}^{-} \longrightarrow \mathrm{M}^{++}+2 \mathrm{e}^{-} \text {at the anode } \quad \ldots . .(2)
$$

Where, $\mathrm{M}$ is a divalent metal. comparable responses likewise happen to mono and trivalent metal. Disintegration of anode metal to shape metal salts can be treated as a procedure of oxidation while metal testimony on the cathode surface as the decrease procedure. So when the metal is saved on the cathode equal measure of metal particles ought to likewise go into arrangement from the anode.

\subsection{Warm decay (or) pyrolysis}

Numerous halides or organometallic mixes when warmed to high temperatures decays bringing about the arrangement of strong and vaporous stage. By and large a few phases of auxiliary gas likewise delivered which would then be able to be deteriorated with the ideal strong film. In this way, when the silicon organometallic mixes, for example, tetra ethoxy silane, tetra ethylene ortho silicate (TEOS) and so on. The fluid in (temp) structure is warmed to a temperature of around 700-900 ${ }^{\circ} \mathrm{C}, \mathrm{SiO} 2$ dielectric film is framed as appeared by following eqn,

$\mathrm{Si}\left(\mathrm{OC}_{2} \mathrm{H}_{5}\right)_{4}$ decomposes to $\underset{\mathrm{SiO}_{2}+4 \mathrm{C}_{2}}{\longrightarrow} \mathrm{H}_{4}+\mathrm{H}_{2} \mathrm{O}$

\section{EXPERIMENTAL TECHNIQUES USED IN THE PRESENT STUDIES}

\section{2,1 Spray pyrolysis}

Shower pyrolysis is a warm animated response between fluid fume nuclear bunches of various compound species. The methods of splashing includes showering an answer containing disintegrated salts of the ideal compound constituent iotas on the substrate is kept up at a high temperature. The splashed beads on arriving at the hot substrate under pyrolytic disintegration proceed to single precious stone bunch clusterllites items.

The other unstable items and abundance departure of dissolvable in the fume stage. The warm vitality for the decay and resulting recombination of species and recrystallization of the crystallites are given by the hot substrate. A schematic outline of a shower pyrolysis strategy appeared in figure (5.1).

Atomization substance arrangement into a splash bead shower spout is influenced by the transporter gas with the assistance of the city hall leader may not be engaged with the pyrolytic response.

Sweep either of the splash head and the substrate utilizing a compound electro courses of action accomplish a huge zone, uniform inclusion of the substrate.

Synthetic concoctions utilized for splash pyrolysis must meet the accompanying prerequisites.

A. the ideal slight film material to be acquired because of thermally initiated responses between different species/complex broke down in the shower arrangement.

b. The remainder of the constituent synthetic concoctions including fluid bearer should be steady at pyrolytic temperature.

$\square$ The development of the film by splash pyrolysis is dictated by

a) The nature of the substrate.

b) The science and focus.

c) Spray parameter.

Typically the development rate in the scope of 500 to $1000 \mathrm{~A} 0 / \mathrm{min}$ was acquired for the oxide film. the substrate surface is influenced during the time spent splash and the decision is constrained to glass, quartz, fired oxides, nitrites or carbides, covered substrate. Metal substrates are seen as reasonable for this procedure.

Shower kept movies are commonly accommodating solid, hard mechanical, stick gap free and stable with time and temperature. Spout size will decide the example, shower bead size conveyance and splash level. Doped and blended movies can likewise be made by including a shower arrangement, dissolvable salts, the ideal dopant or polluting influence. 


\section{Spray Pyrolysis Method}

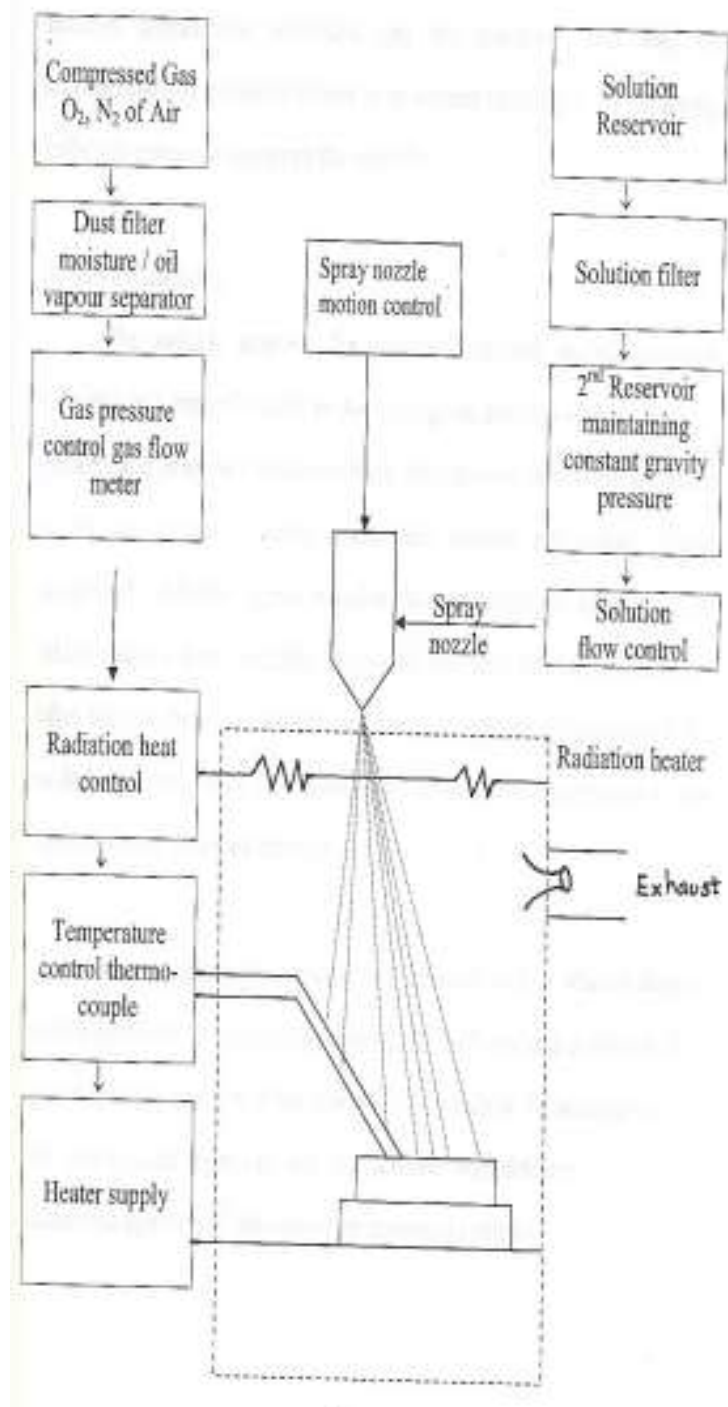

\subsection{Solution Preparation}

arrangement of nickel chloride $(\mathrm{NiCl} 2,6 \mathrm{H} 2 \mathrm{O})$ and stannous chloride $(\mathrm{SnCl} 2.2 \mathrm{H} 2 \mathrm{O})$ arranged with the aid of molarity zero.1 M and $0.01 \mathrm{M}$. Nickel chloride Hydro dissolvable in concentrated hydrochloric corrosive whilst warmed. Nickel chloride and stannous chloride are mixed in diverse proportions, zero.1: zero.02M, zero.1: zero.03 M one by one.

Atomic weight $=237.71$ grams of nickel chloride and stannous chloride $=225$. sixty three grams. The arrangements are showered utilising a splash weapon with a pyrolytic method on a solitary glass substrate wherein the consistent temperature of $360^{\circ} \mathrm{C}$ is stored up. Showering turned into proceeded till uniform film framed at the substrate, that's additionally executed by means of putting the substrate at the proper right ways from the wellspring of the splash and furthermore pivoting the substrate either hub or from the source or nicely as the necessities of the case.

\section{3. trial techniques}

$\square$ R T version Spray Pyrolysis technique

$\mathrm{R}$ - model $\mathrm{T}$ of bathe pyrolysis set accommodates of a dash weapon based locals glass established in a quart glass balls as regarded within the discern. the distance throughout of the glass bulb is $12 \mathrm{~cm}$. The breadth of the spout of the bathe weapon association was zero. $5 \mathrm{~mm}$.

bathe weapon was put vertically in a one liter glass balls and a solution this is splashed into the glass bulb. Glass ball has shops. One outlet is related to a deliver of the association thru the " $\mathrm{T}$ " putting, so abundance splash arrangement at some stage in the reusing and waste preparations on this way stayed away from as within the everyday bathe pyrolysis system that is a great drawback. exclusive circuits (outlet fog) is set with the goal that it's miles entirely expected to the substrate. Fog containing reactant atoms pass via the fog stores and falls commonly at the substrate is warmed. in this manner the movie became acquired with this set up is in nano precious stone and comply with an assortment of substrates.

$\square$ settings Experimental

The arrangement organized is utilized in splashing on is chosen, the substrate is cleaned with the right arrangement of trials, regarded in the parent, that's dependent explicitly for pyrolysis.

$\mathrm{V}$ The number one piece of the exploratory set-up,

$\square$ chrome steel warming container is kept up at a regular temperature. utilizing the indoor regulator.

$\ddot{U}$ splash weapon to bathe an answer organized.

$\square$ Compressed air supply.

$\square$ solution deliver (typically glass).

Splash weapon has two gaps, one related to the compacted air save and others associated with the repository arrangement. The breadth of the bathe weapon is $0.0425 \mathrm{~cm}$.

The pneumatic strain is predicted by a weight degree. electric powered radiator with indoor regulator is utilized to warm the substrate. The substrate temperature is predicted with thermocouples.

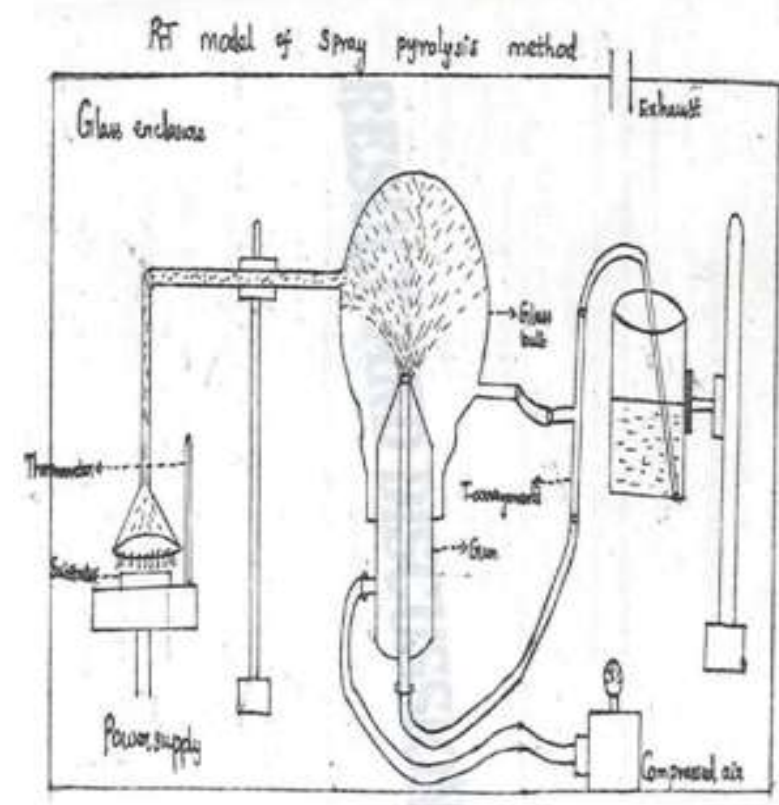




\section{A ELECTRICAL AND OPTICAL CHARACTERISTICS OF STANNOUS DOPED NICKEL OXIDE THIN FILM FORMED BY SPRAY PYROLYSIS TECHNIQUE}

\section{IV.. RESULT AND DISCUSSION}

\section{Thickness}

Film thickness is measured using microbalance method. The thickness of the coated films are given in the below table.

\section{Resistance}

Film resistance is determined by computer controlled keithley electrometer and the resistance of the coated films are given in the below table.

\section{Optical Characteristics}

\section{Absorption}

This refers to the taking in the energy of the radiation. This is a process where gas is taken by liquid or solid, or liquid taken up by solid. Absorption hygrometer used to measure air humidity. To measure the humidity, the air is allowed to pass through a weighted sum of the drying agent and subsequently an increase in weight is determined.

Studies coated film absorption to different wavelengths studied using makeup Elico spectrophotometer. A graph is drawn between the wavelengths along the $\mathrm{x}$ and Absorption along the $y$-axis for each of the three films Nickel oxide doped stannous.

\section{Energy Band Gap}

The energy band gap of the film is determined by plotting a graph between $\left(h^{\vee}\right)$ Vs $\left(\alpha h^{\vee}\right)^{3 / 2}$ and the corresponding optical energy band gaps are given in the below table.

\section{CONCLUSION}

This film of nickel oxide doped stannous organized on a pitcher substrate at $360^{\circ} \mathrm{C}$ with a bath pyrolysis technique. Nio: Sn movies formed on numerous proportions, for instance, zero. $1 \mathrm{M}$ molarity: $0.01 \mathrm{M}$ and $0.1 \mathrm{M}$ : zero.03M. The movies were observed uniform and disciple to the substrate. its thickness become expected utilizing a smaller scale balance method. the electrical obstruction is anticipated by means of a computer managed Keithley electrometer and ingestion and energy band hole determined for diverse wavelengths utilizing a spectrophotometer Elico cosmetics.

it is presumed that, the electric competition of blanketed movies is elevated whilst expanding the molarity percentage of stannous. similarly, it was found that the energy band hole likewise dwindled while increasing the molarity share of stannous.

\section{REFERENCES}

1. Anderson, J., "Meager movie Physics".

2. Faraday, "Meager movie Physics" 147 , a hundred forty five (1857).

3. Goswami, A., "Meager movie fundamenals" New Age worldwide (P) limited Publishers, (1996).

4. woodland, W.R. "narrow movie Physics" (1852), Trans. Roy. Soc. London, 142.87.

5. Holland, L., "vacuum affidavit of narrow movies" John Wiley and Sons, Inc., ny, 1956.

6. Lennard Jones, "Proc. Roy. Sac"., London A 163, 127 (1937).

7. Malhotra, "mild movie Physics"

8. Nahrowold, R., Ann Physik. 31467 (1887) 